\title{
REMARKS ON SOME POINTS
}

AFFECTING THE

\section{MORTALITY OF ABDOMINAL SECTION.}

WITH TABLES OF CASES.

BY

W. A. MEREDITH, M.B., C.M., SURGEON TO THE SAMARITAN FREE HOSPITAI.

Received February 14th-Read October 23rd, 1888.

THE purpose of this paper-as stated in its title-is to draw attention to certain points affecting the present rate of mortality after abdominal section, as compared with that which prevailed so recently as ten years ago.

The progress made in all branches of abdominal surgery since 1877 would afford altogether too wide a field for discussion; and I therefore propose to limit my remarks to operations for ovarian growths, as being to some extent representative of the entire question under consideration.

As a basis for the inquiry, I have taken the results of my own work in connection with diseases of the ovary up to the end of 1887. The cases, here recorded in a tabulated form as affording the readiest means for identification and reference, consist of 104 completed ovariotomies, and of 
twelve cases of removal of diseased uterine appendages. To these two I have added a third group containing four incomplete operations and six exploratory incisions, in order to complete my list of ovarian operations to the abovementioned date.

The details appended in the Tables sufficiently indicate, in most instances, the nature and consequences of the individual operations, thus rendering further allusion to the majority of them unnecessary. Certain facts connected with the first two groups require, however, to be noted; and special reference will be made to the fatal cases contained in the ovariotomy series.

All my operations have been performed with strict antiseptic precautions, including the use of the carbolized spray : and I will first allude to this method of treatment, because I believe that the increased success of peritoneal surgery at the present day is in great measure-directly or indirectly-attributable to the outcome of the teaching of Lister.

Having early acquired a strong faith in the value of carbolic acid during my residence in Edinburgh, I was still further influenced in favour of antiseptics when I began working at abdominal surgery in 1881, by the success then attending their use in the hands of my colleague $\mathrm{Mr}$. Thornton at the Samaritan Hospital; and the fact that I lost only two patients out of my first thirty ovariotomies, proved a very decided encouragement to pursue the system rigidly. I have accordingly continued to use it, and so far, see no reason to regret having done so. For some time past I have been less inclined than formerly to look upon the spray as an absolute essential to the safeguards of antiseptic abdominal surgery; but I still consider it valuable as the most convenient and effectual means of antiseptic irrigation at our disposal when dealing with the peritoneal cavity; and for this reason I still employ it.

The fact that certain operators who formerly used antiseptics now obtain improved results with the help of plain water and the systematic employment of the drainage-tube, by no means convinces me that their present success is 
entirely due to the alteration in their system of treatment. Such an argument would quite ignore the influence of increased skill and experience-two factors which must of necessity largely affect the attainment of success in abdominal work, as in any other department of surgery.

The consecutive series of 104 completed ovariotomies recorded in Table $I$, includes ninety-six cases of ovarian tumour, and eight cases of parovarian or broad-ligament cysts.

Of these patients, seventy-three were operated on in hospital ; while the remainder, thirty-one in number, were treated in nursing homes or in private houses. Reference to the Table will show that the relative mortality of the two groups was as nearly as possible equal.

Both ovaries were taken away in seventeen cases, two of which terminated fatally (Nos. 60 and 90 ) ; but in neither instance was the result in any way attributable to the removal of the second ovary.

Adhesions, resulting from more or less extensive inflammatory action, were met with in fifty-six cases, in forty-five of which they were of a nature to increase the risks of the operation. Among this latter number are included seven fatal cases.

Partial enucleation of the tumour was required in seventeen cases, and four of these patients died. In five other cases complete enucleation was performed, the resulting rent in the broad ligament being in each instance subsequently closed by means of a continuous suture of fine silk after all hæmorrhage had been arrested. These latter patients all did well, and I believe that the plan here adopted of accurately repairing any extensive injury inflicted on the pelvic peritoneum during the removal of a broad-ligament growth, is one which may be followed with advantage.

Eight of the patients had been tapped previously to operation, and of these two died. I do not here propose to discuss the question of this treatment, but will merely state my most cordial agreement with the opinion expressed vol. LXXII. 
before this Society by Mr. Thornton in $1886,{ }^{1}$ when-speaking of the dangers incurred through tapping ovarian and parovarian or broad-ligament cysts, he alluded to the practice as both "unscientific and pernicious." The truth of this criticism will, I believe, be pretty generally admitted at the present day; but I may nevertheless briefly refer to one of the above-mentioned cases (No. 58) as serving to illustrate the appropriateness of the term "unscientific" applied to the procedure in question.

The patient, a lady sixty-eight years of age, first consulted me in October, 1884, on account of the presence of a large flaccid abdominal cyst. She stated that she had been once tapped, twenty-five years before, i.e. in 1859, by the late Sir William Fergusson, who considered the fluid then drawn off as characteristic of an ovarian tumour. The cyst, however, did not refill as expected; and from that date she remained in good health until within two years of my seeing her, when the abdomen again began to enlarge. At the operation I removed a unilocular non-adherent ovarian cyst, containing twenty-two pints of fluid laden with cholesterine. The left ovary was atrophic. Subsequent examination of the cyst tended fully to confirm the opinion as to its probable identity with the original cyst which had been tapped twenty-five years before, and had presumably since then lain quiescent until within two years of its successful removal.

This case, which, in my experience, is unique as regards its history, forcibly illustrates the fallacy of the theory that simple withdrawal of the fluid from a closed secreting cyst can be followed by final obliteration of its cavity, at all events in the case of ovarian growths. That the same holds true in regard to parovarian or broad-ligament cysts, is more than probable from what we know of their structure and secreting properties; and this view is further supported by the well-ascertained fact that tapping in such cases is as a rule followed by more or less speedy reaccumulation of the cyst fluid.

1 'Med. Chir. Trans.,' vol. 1xx, p. 49. 
Drainage of the peritoneal cavity was carried out in eighteen instances; and of these no less than fifteen are included among the latter half of my cases-a fact to be chiefly accounted for, I believe, on the grounds of increased experience in the management of the tube, and consequent increased belief in its usefulness in certain conditions. ${ }^{1}$

A point to which I would draw attention in connection with this subject is the age of these eighteen patients who were drained. If one excludes three cases where the tube was used on account of special operative complications, viz. incomplete removal of an adherent Fallopian tube (No. 86), injury to bladder (No. 89), and escape of fluid from a dermoid cyst, necessitating washing out of the peritoneal cavity (No. 94), it may be seen on reference to the Table that the average age of the fifteen remaining patients exceeded fifty years, ranging from forty-one to sixty-three.

Allusion to this fact is made in support of the opinion that the cases requiring drainage are, as a rule, those of women who are passing through, or have recently passed, the menopause.

In patients under forty the tube is very rarely needed after antiseptic ovariotomy, unless in exceptional circumstances. But in older women its employment is more often advisable. Such patients are not unfrequently the subjects of some amount of latent renal mischief, which may declare itself only too plainly when the extra work entailed upon the kidneys by the attempt to carry off peritoneal fluids, comes to be encountered. Under such conditions, I believe that the tube may prove of the greatest value.

With my present views on this question, I consider drainage advisable :

1. In cases of ruptured or inflamed cysts, especially when tapping has preceded the major operation.

2. In any case where fluid of an irritating or possibly

1 Of 3 drainage cases among my first 52 patients 1 recovered and 2 died; while out of 15 such cases included in my second series of 52, 12 recovered and but 3 died. 
septic nature has escaped into the peritoneal cavity during the removal of a cyst or of a dilated tube.

3. In all operations complicated by serious injury to bowel or urinary bladder.

4. In every instance where washing-out of the peritoneal cavity has been resorted to, whether on account of preexisting sepsis, or for the purpose of removing extravasated fluid or blood-clot.

5. Finally, in all cases of severe operation in middle-aged or elderly women, my rule would be, when in doubt, to drain. The tube, if properly managed, can do no harm, and I am convinced that not only is it often most useful in promoting a speedy and uneventful convalescence, but that it not unfrequently saves life.

A kindred subject to that of drainage is the washing-out of the peritoneal cavity. My own experience of this treatment has so far been limited to but three cases-one of ovariotomy and two of hæmatosalpinx (see Tables I and II) ; but I have watched its results in a large number of instances, and am much impressed by its efficacy in cases where no antiseptic precautions have been used during operation.

From the standpoint, however, of one who still believes. in the value of such precautions, as compared with simple cleanliness, I cannot but feel that the system, in its general application to abdominal surgery, is not as yet perfected, since we lack an antiseptic which can with safety be used for thus freely cleansing the peritoneal cavity, in sufficiently strong solution to ensure destruction of pre-existing sepsis. Meantime, I believe that plain, recently-boiled water, to be cooled as required by the addition of a saturated solution of boracic acid, is the best thing to employ for this purpose in putrid cases.

The use of a blunt-pointed siphon tube, whereby the inflowing stream is conveyed direct to the pelvis, will tend to avoid the spreading upwards among the intestines of septic particles, which might thence escape removal by the outgoing stream of water. 
Of the 104 patients included in this series (Table I), ninety-four recovered and ten died. Such a mortality$9 \cdot 6$ per cent. - compares not unfavorably with that of $13 \cdot 2$ per cent. shown in the combined records of 512 ovariotomies published in the "Transactions"l of this Society so recently as in 1881 ; but it is still in excess by at least a third of what one may reasonably hope, with increasing experience, to attain to in the future.

At the same time I am not much inclined to believe that, even in the hands of the most skilful, any really large series of operations for the removal of ovarian tumours will show an average death-rate of less than 5 or 6 per cent., although the long lists of fortunate recoveries occasionally met with in medical literature might appear to warrant a different assumption. My view of the subject is, however, supported by the fact that so experienced an operator as $\mathrm{Mr}$. Thornton, in his latest published series of 300 operations, has not reduced his average mortality below 7 per cent. 2

In attempting to analyse the causes of failure in my ten fatal operations, I have grouped them as follows, the numbers appended corresponding in each instance with those in the Table.

Septicæmia (two deaths).-No. 14 was a case of putrid cyst with a twisted pedicle and universal adhesions. The patient, who had been recently confined, was extremely ill, and suffering from the effects of septic absorption at the time of operation. She died of blood-poisoning on the fourth day.

No. 31, a most unfortunate case, terminated fatally after a perfectly simple ovariotomy, from well-marked septicæmia due to infection conveyed through the sponges used at the operation.

Intestinal obstruction (one death).-No. 53, a feeble old woman, died on the fifteenth day after operation, worn out by persistent vomiting during the last week of her life. This was found post mortem to have resulted from a twist

1 'Med. Chir. Trans.', vol. lxiv, pp. 103-183.

2 Ibid., vol. lixx, p. 44. 
of the ileum above the seat of an adhesion between the gat and the back of the uterus. A timely reopening of the abdomen would in all probability have saved the patient's life, and my only consolation is that the lesson here taught me proved useful in a later case (No. 67),' where prompt operative interference under similar conditions was followed by complete recovery.

Hæmorrhage (one death).-No. 90, a simple ovariotomy, complicated only by the removal of the second ovary. Symptoms of internal hæmorrhage followed within a couple of hours of the patient's return to bed, but I was unfortunately not sent for until too late. On reopening the abdomen the outer loop ligature on the tumour pedicle was found to have slipped, permitting retraction of the ovarian artery. This was secured by a fresh transfixion and ligature of the broad ligament; the clots were then cleared out, and the abdomen was closed after insertion of a drainagetube. The patient, who had lost an enormous quantity of blood, never rallied, and died in the course of the night.

Dysenteric diarrhoea (one death).-No. 60, a delicate woman with a tuberculous history, died on the ninth day after operation from exhaustion due to uncontrollable diarrhœa. Post-mortem examination revealed extensive dysenteric ulceration of the colon. Both kidneys were much diseased.

Chest complications (two deaths).-Both these followed on the removal of large tumours from aged and very feeble women, the subjects of chronic bronchitis.

No. 15 died on the fifth day with symptoms of general pulmonary œdema, the abdominal condition remaining satisfactory to the last.

No. 77, after doing well for forty-eight hours, was being raised in bed on the morning of the third day, when she suddenly collapsed and died, presumably from embolism.

Exhaustion (three deaths).-No. 44, a case of malignant tumour with ascites, complicated by the presence of a 
greatly enlarged liver and extensive general anasarca, died on the third day from what appeared to be simple exhaustion.

The two remaining cases both died from the immediate effects of very severe and prolonged operations.

No. 93 was one of rapidly growing malignant dermoid tumour with universal adhesions. The patient never rallied fully from the shock, remaining extremely prostrate, with a barely perceptible pulse. She grew steadily weaker, and died thirty-six hours after operation.

No. 96. The removal of a semi-solid tumour was greatly complicated by universal adhesions, including very extensive intestinal connections. After regaining consciousness the patient seemed fairly well but for the fact of an extremely feeble circulation, which was quite unaffected by stimulants. She became gradually comatose, and died on the second day.

In three out of these ten fatal cases death was directly due to preventable causes,-Nos. 31, 53, and 90. For these fatalities I entirely blame myself. The remaining seven resulted from causes more or less beyond my control, but I trust that the lesson learnt from each one of them may prove of help to me in dealing more successfully with similar conditions in the future.

Table II contains twelve cases of removal of one or both uterine appendages for disease connected with persistent suffering.

All of these patients recovered, and, with the exception of one (No. 7) who died eleven months after operation from acute tuberculosis, all were in good health when last heard from. The report appended under the heading of Ultimate Result has in every instance been obtained direct from the patient herself.

Nine out of the twelve were chronic cases with a history of more or less constant suffering of from two to ten years' duration, and in none of these was operative interference undertaken until a prolonged trial of other treatment had failed completely either in my own hands, or in those of 
someone on whose statements with regard to this point I could fully rely.

The three remaining cases, Nos. 7, 11, and 12, were operated on for the relief of acute symptoms of comparatively recent date (see Table).

In seven of the patients (four married and three single women) both appendages were removed, the operation in each instance being followed by entire relief from pain and by complete arrest of menstruation. A like result was obtained by the removal of the remaining ovary in the married woman (No. 7) who had previously undergone ovariotomy.

Among the four other patients, from whom only one appendage was taken away, the second ovary was found healthy in two (one married and one single woman), who have since menstruated without pain. In the remaining cases (both married women, Nos. 9 and 12), the second ovary, although diseased, was not removed for the reasons stated in the Table.

Some experience in the management of these cases of chronic ovarian mischief has led me to the opinion that the pain accompanying them, which may amount to severe and almost constant suffering in hospital patients who are compelled to work for their living, can in most instances be considerably alleviated by the use of purgatives. Roughly estimating, I should say that from 80 to 90 per cent. of such cases are the subjects of more or less obstinate constipation, due in great measure, I believe, to dread of the pain experienced during defæcation from the pressure then exerted upon the prolapsed and often exquisitely tender ovaries.

Under such conditions a judicious course of tonic purgative treatment, by lessening pelvic congestion and preventing the formation and passage of scybala, is usually followed by marked relief of symptoms with a corresponding improvement in general health.

In a certain small proportion of cases, however, including especially those complicated by suppurative or hæmorrhagic 
disease of the tubes, any mode of treatment short of operation fails ultimately in affording relief. The pain, originally confined to the menstrual periods, recurs with varying intensity during the intervals, becoming gradually more and more persistent in character, while constantly aggravated by exertion of any kind.

In cases of this nature, where tangible evidence of disease involving the uterine appendages exists, I believe that operative interference, as a last resort, is occasionally justifiable, and, moreover, likely to prove successful as regards ultimate restoration to health.

The operation is, however, one which, for obvious reasons, should be most carefully limited in its application; and, even when advocated in properly selected instances, it should never, in my opinion, be undertaken until the patient and her husband (or nearest relative if she be unmarried) have been made to fully appreciate not only the immediate risk to life entailed by the contemplated procedure, but also the possible consequences involved with regard to her future in all its bearings.

Table III requires but brief mention, as the details therein given sufficiently explain the nature and consequences of the operations recorded in it. Among the incomplete cases are included the only two instances in which I have as yet failed in the attempted removal of an ovarian tumour. Both of these patients had been tapped, and the death of the second one, who was the subject of a very large multilocular growth, was directly due to the difficulties encountered in the attempt to separate universal adhesions which had resulted from this treatment.

In tracing the main factors which have led to the increasing success of abdominal section during the past ten years, one cannot fail to be impressed by the marked decrease in the number of deaths from septicæmia-a cause which formerly figured so largely in the mortality of ovariotomy.

For purposes of comparison I will take three groups of operations as illustrative of this fact.

The first of these, consisting of 100 cases, numbered con- 
secutively from 701 to 800 , is contained in the record of 1000 completed ovariotomies in Sir Spencer Wells's work on 'Ovarian and Uterine Tumours' (edition of 1882, pp. 378 to 382 ). My object in selecting this special series is to show the mortality from septicæmia which prevailed. during the use of the clamp, and previously to the employment of antiseptics in abdominal surgery.

The second group consists of 150 ovariotomies recorded by Mr. Thornton in the sixty-fourth volume of our 'Transactions' (pp. 139 to 161). All of these cases were treated by intraperitoneal ligature of the pedicle, and the operations were, moreover, performed with antiseptic precautions.

The third group contains my own present series of 104 ovariotomies.

The following figures will show the average death-rate from septicæmia alone in these three groups, representing three successive periods during the last twelve years :

I. $1875-76.100$ cases, 10 deaths, or 1 to every 10 patients.

II. $1877-80$. 150 cases, 5 deaths, or 1 to every 30 patients.

III. 1881-87. 104 cases, 2 deaths, or one to every 52 patients.

These results certainly tend to prove that one great cause of the former mortality following ovariotomy has now to a great extent been brought under control, and this fact has undoubtedly influenced the general death-rate in all departments of abdominal surgery.

It only remains for me in conclusion to enumerate the chief factors which, in my opinion, have contributed to this increased success. These are :

1. The general adoption of the intraperitoneal treatment of the ovarian pedicle.

2. The application of the antiseptic system to abdominal surgery.

3. The gradual abandonment of the practice of tapping abdominal cysts. 
4. The increase in our knowledge respecting the proper use and management of the drainage-tube.

5. And, lastly, the recent introduction of the plan of washing out the peritoneal cavity in cases complicated by the extravasation of blood or other fluids.

Note.

Since reading the above I have discontinued the use of the spray, while still employing carbolic acid for instruments, silk, and sponges; and the result of my past twelve months' experience fully confirms me in the wisdom of this step. 


\begin{tabular}{|c|c|c|c|c|c|c|c|c|c|c|c|}
\hline 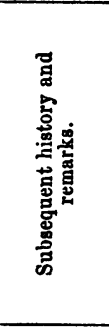 & 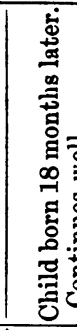 & 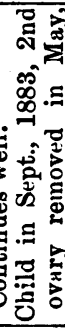 & & & 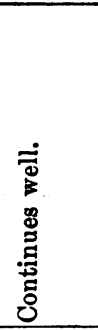 & 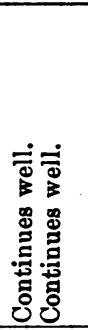 & 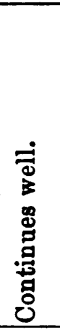 & 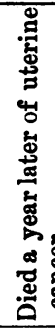 & 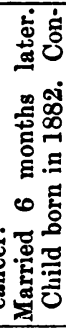 & 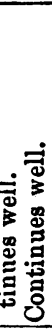 & 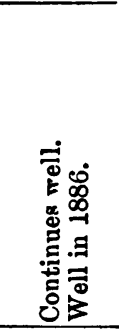 \\
\hline 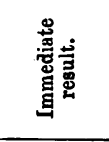 & 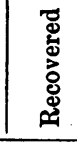 & 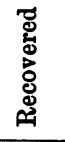 & 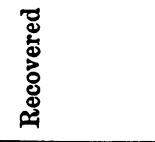 & 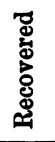 & 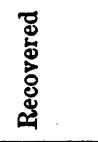 & 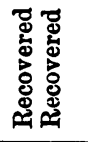 & 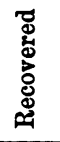 & 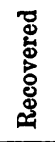 & 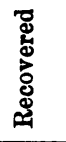 & 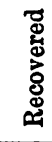 & 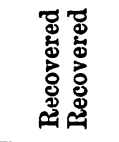 \\
\hline 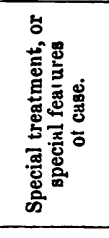 & 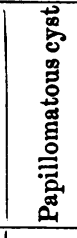 & 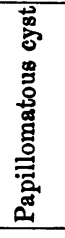 & 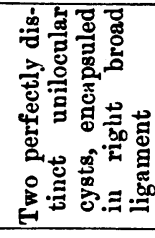 & 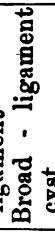 & 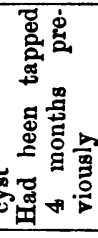 & $\begin{array}{ll}1 & 1 \\
& \end{array}$ & 1 & I & 1 & I & 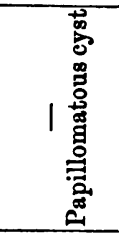 \\
\hline 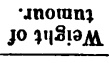 & 里涪 & \& & $\stackrel{-}{0}$ & ลี & $\stackrel{\wp}{\circ}$ & बㅋ & ลี & $\Rightarrow$ & $\infty$ & $\Rightarrow$ & ตึస \\
\hline 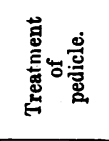 & 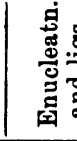 & 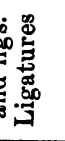 & 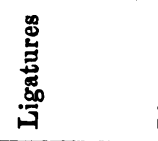 & 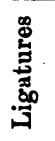 & 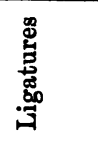 & 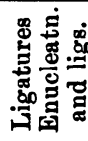 & 递 & 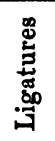 & 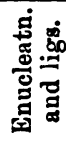 & 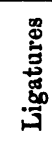 & 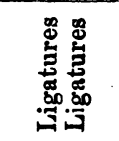 \\
\hline 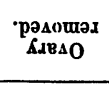 & 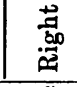 & 岕 & 营 & 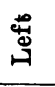 & 壳 & 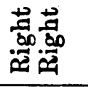 & 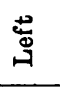 & 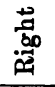 & 营 & $\underset{00}{30}$ & 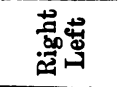 \\
\hline 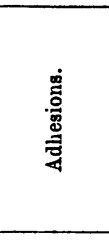 & 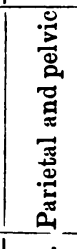 & 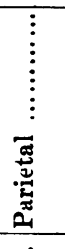 & $\begin{array}{c}\vdots \vdots \\
\vdots \\
\vdots \\
\vdots \\
0 \\
\vdots \\
\vdots\end{array}$ & $\begin{array}{c}\vdots \\
\vdots \\
\vdots \\
\vdots \\
\vdots \\
\vdots \\
\end{array}$ & 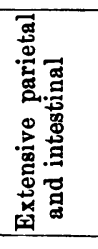 & 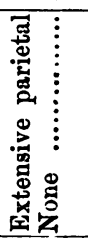 & 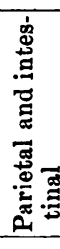 & $\begin{array}{c}\vdots \vdots \\
\vdots \\
\vdots \\
\vdots \\
\vdots \\
\vdots \\
\vdots \\
z\end{array}$ & 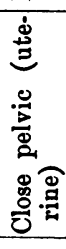 & 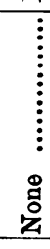 & 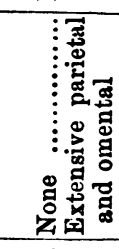 \\
\hline 'uo!̣!̣puos & $\dot{\lambda}$ & $\dot{\Sigma}$ & $\dot{\Sigma}$ & $\dot{\Sigma}$ & $\dot{\Sigma}$ & $\dot{\varphi} \dot{\Sigma}$ & $\dot{\Omega}$ & $\dot{\lambda}$ & $\dot{\boldsymbol{\Omega}}$ & $\dot{\Sigma}$ & $\dot{\nabla} \dot{\theta}$ \\
\hline$\cdot 28 \mathrm{~V}$ & ลำ & ล & 命 & ఝ్ల & $\stackrel{\infty}{+}$ & ลิ & $\bar{n}$ & 8 & 禺 & ๙్ల & 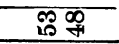 \\
\hline 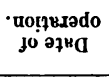 & $\mid \begin{array}{l}\infty \\
\infty \\
\infty \\
0\end{array}$ & $\dot{8}$ & 㻤 & $\stackrel{\Xi}{\Xi}$ & $\stackrel{2}{\Xi}$ & 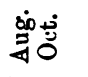 & $\dot{\Xi}$ & ठீ & 芒 & சீं & 总 \\
\hline 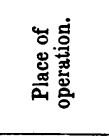 & 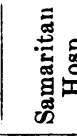 & 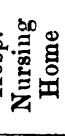 & 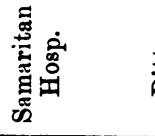 & 䓌 & 总 & 善量 & 总 & 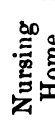 & 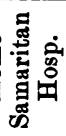 & 总 & 美疍 \\
\hline$\dot{8}$ & $\pi$ & N & $\infty$ & $\pi$ & $\infty$ & ON & $\infty$ & $\sigma$ & 우 & $\exists$ & 雨尔 \\
\hline
\end{tabular}



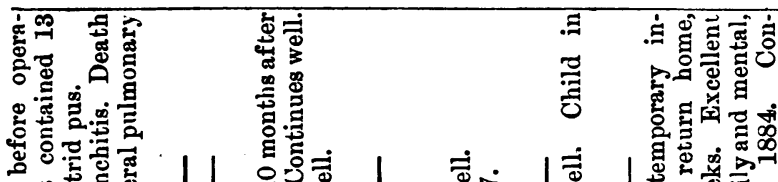

路苔造

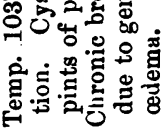

要率

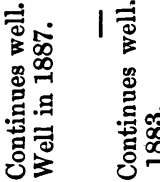

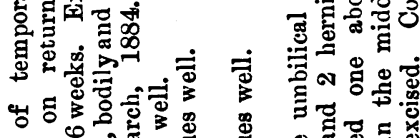

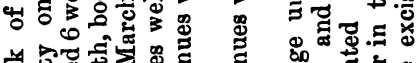

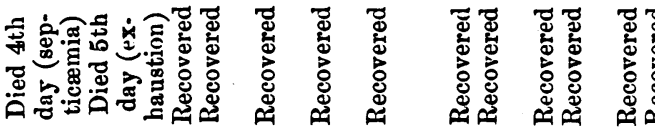

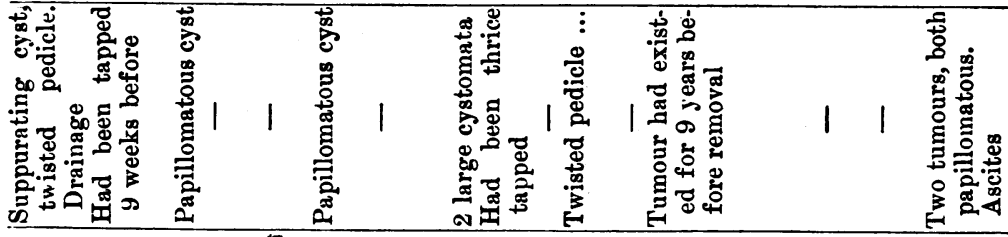

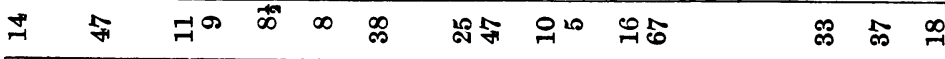

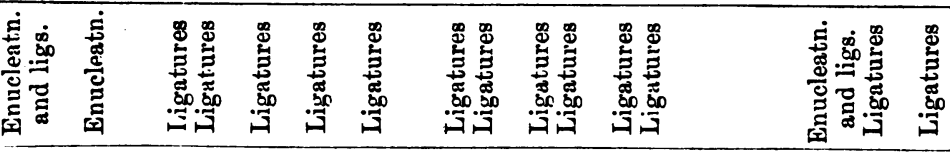

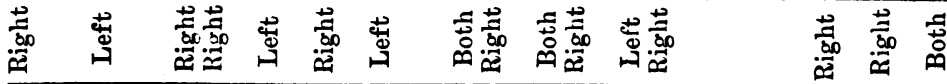

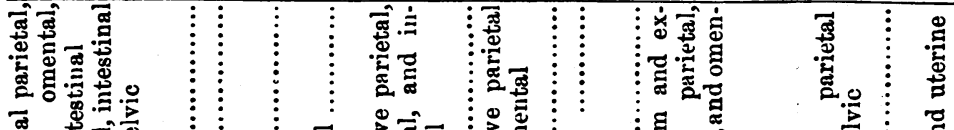

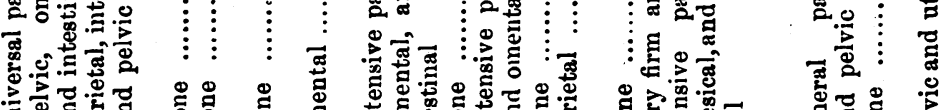

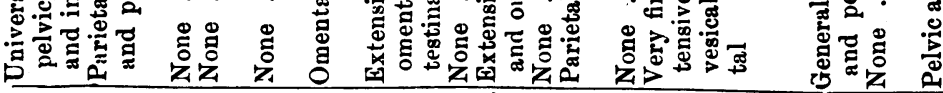

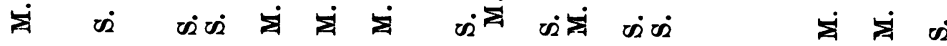

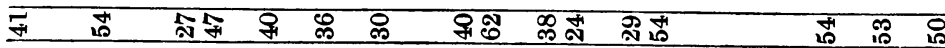

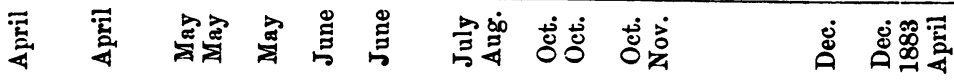

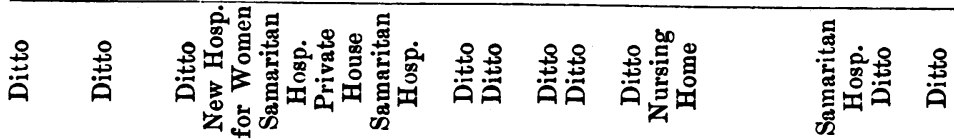

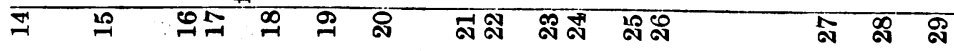




\begin{tabular}{|c|c|c|c|c|c|c|c|c|c|c|c|}
\hline 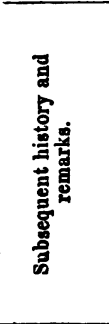 & 1 & 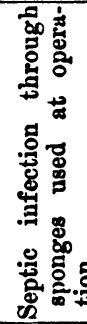 & 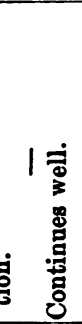 & 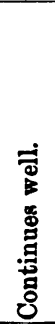 & 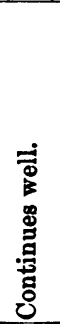 & 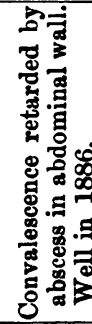 & 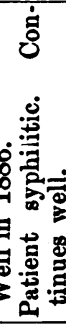 & 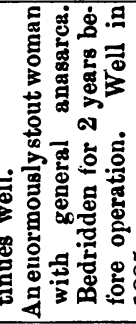 & 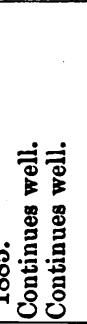 & 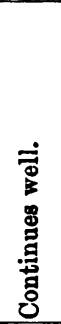 & 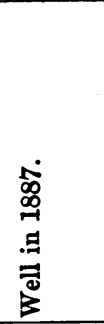 \\
\hline 兽㟒 & 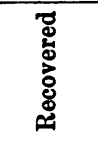 & 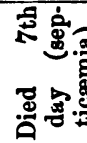 & 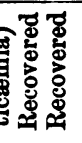 & 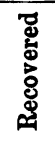 & 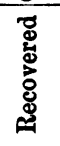 & 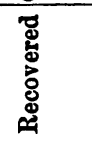 & 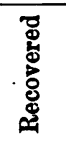 & 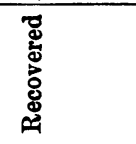 & 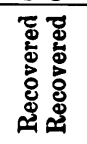 & 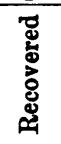 & 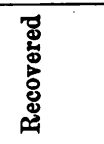 \\
\hline 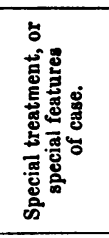 & 1 & I & 11 & 1 & 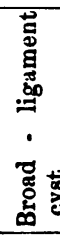 & 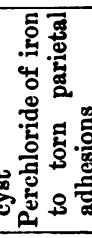 & 造 & 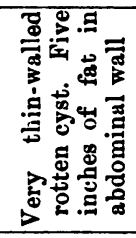 & 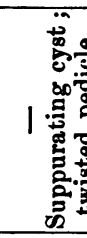 & 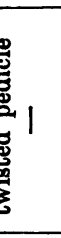 & 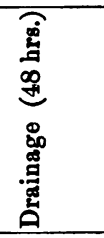 \\
\hline 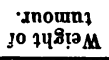 & $\stackrel{0}{\Rightarrow} \frac{0}{\circ}$ & $\stackrel{m}{=}$ & $\Rightarrow 10$ & 10 & $\infty$ & $\approx$ & $N$ & 요 & $\exists$ ت & $\stackrel{\circ}{\circ}$ & ה \\
\hline 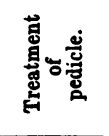 & 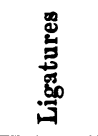 & 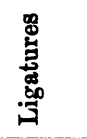 & 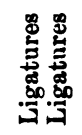 & 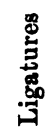 & 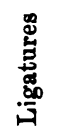 & 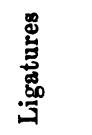 & 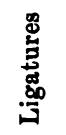 & 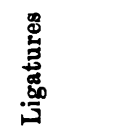 & 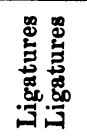 & & 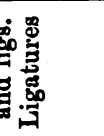 \\
\hline 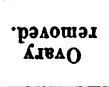 & 若 & 菜 & 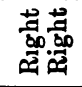 & 营 & 噗 & 苟 & 营 & 离 & 岕芯 & $\stackrel{\rightleftarrows}{\leftrightarrows}$ & 焗 \\
\hline 总 & 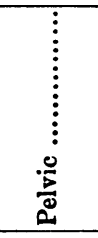 & $\begin{array}{c}\vdots \\
\vdots \\
0 \\
0 \\
\vdots\end{array}$ & 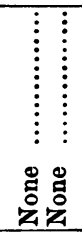 & $\begin{array}{c}\vdots \\
\vdots \\
\vdots \\
\vdots \\
\vdots \\
0 \\
0\end{array}$ & $\begin{array}{c}\vdots \\
\vdots \\
\vdots \\
\vdots \\
0 \\
0 \\
\vdots\end{array}$ & 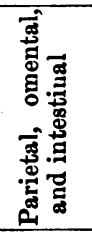 & 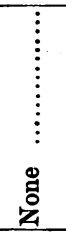 & $\begin{array}{c}\vdots \\
\vdots \\
\vdots \\
\vdots \\
\text { 艺 }\end{array}$ & 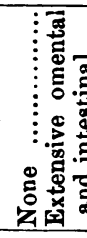 & 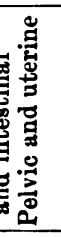 & 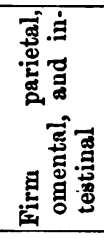 \\
\hline 'иo!̣tpuop & $\dot{\theta}$ & $\dot{z}$ & $\dot{\Sigma} \dot{0}$ & में & $\dot{\infty}$ & $\dot{\mathbf{z}}$ & $\dot{\vec{A}}$ & $\dot{\Sigma}$ & $\dot{\boldsymbol{\infty} \dot{2}}$ & $\dot{\forall}$ & $\dot{2}$ \\
\hline $.28 \mathrm{~V}$ & 유 & פ্ׁ & ஜுణ & 5 & बू & है & ᄋ & 8 & స్ స్ట & 7 & m \\
\hline 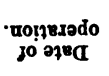 & 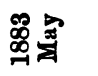 & 佂 & 喿曷 & 煦 & $\stackrel{\Xi}{5}$ & $\stackrel{9}{5}$ & $\stackrel{\Xi}{5}$ & 홈 & $\ddot{\theta}$ & $\dot{0}$ & 客 \\
\hline 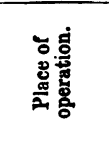 & 宽递 & 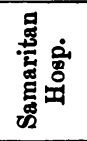 & 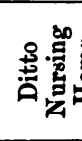 & 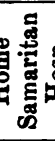 & 它尊 & 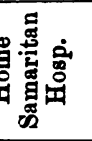 & 兽 & 象点 & 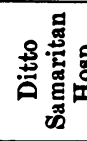 & 语 & 吉 \\
\hline 埌 & ిం & $\bar{\infty}$ & న్ఞ & ตี & $\mathscr{n}$ & $\mathscr{m}$ & 悉 & $\infty$ & 요 & 7 & ศ \\
\hline
\end{tabular}




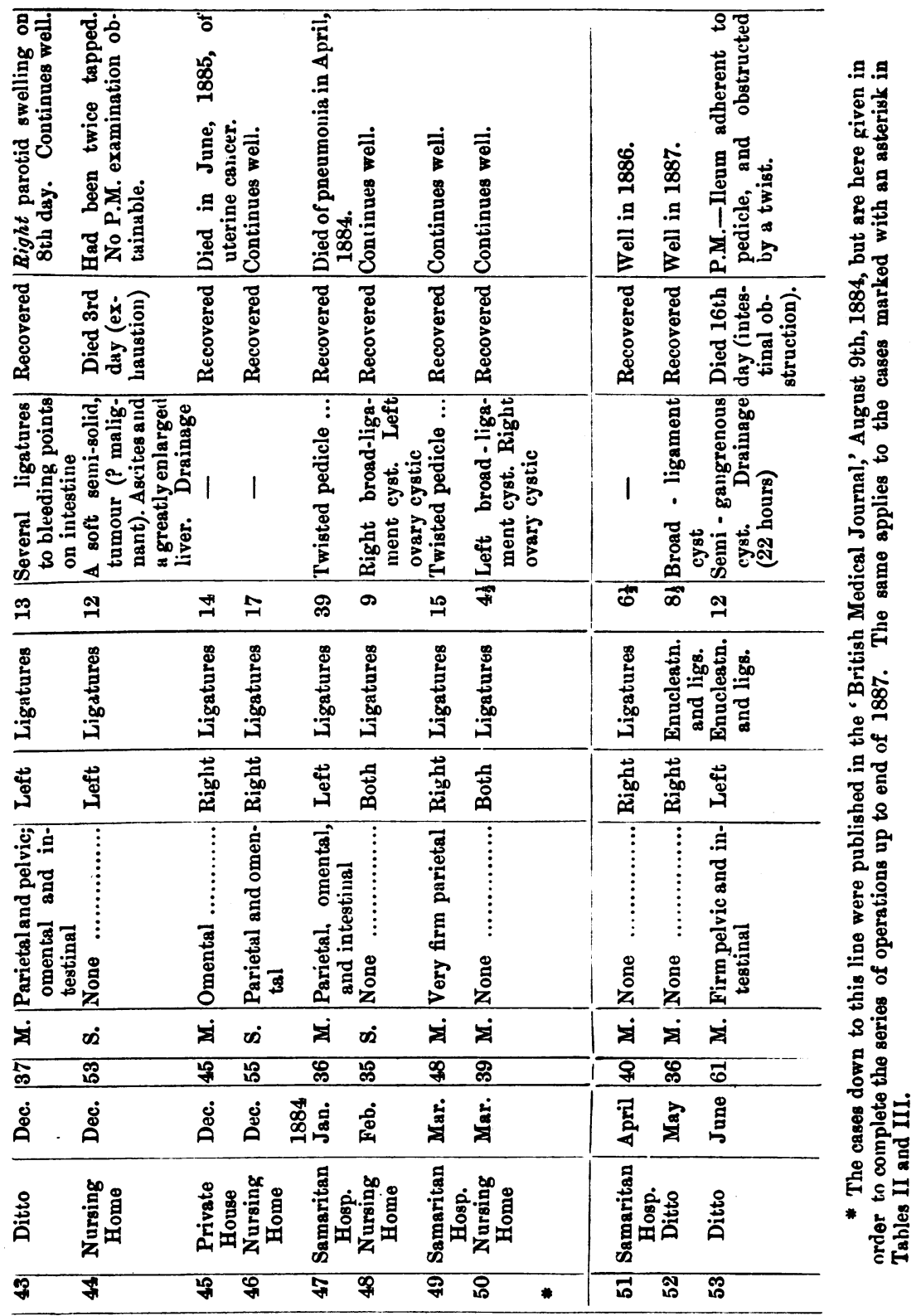




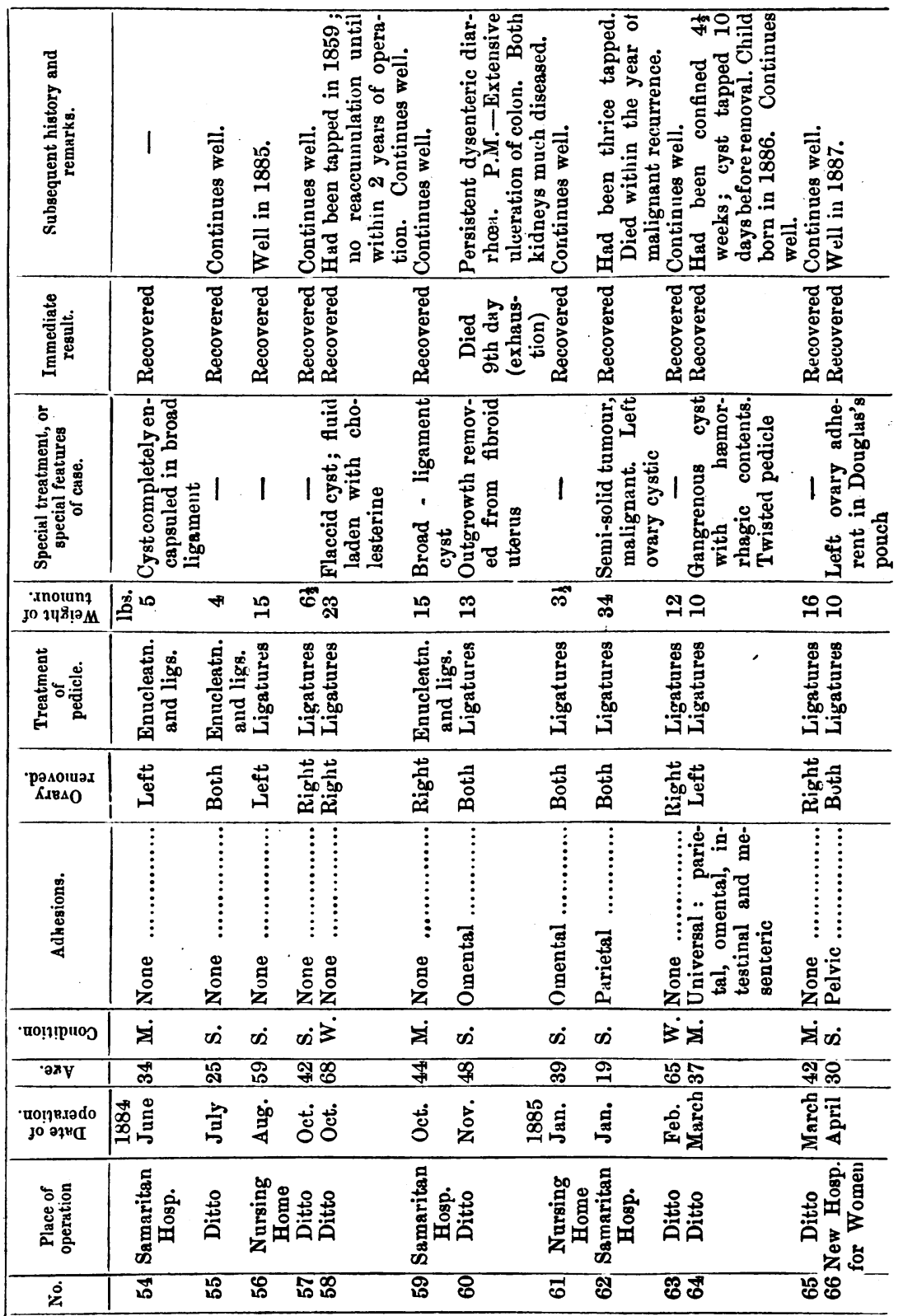




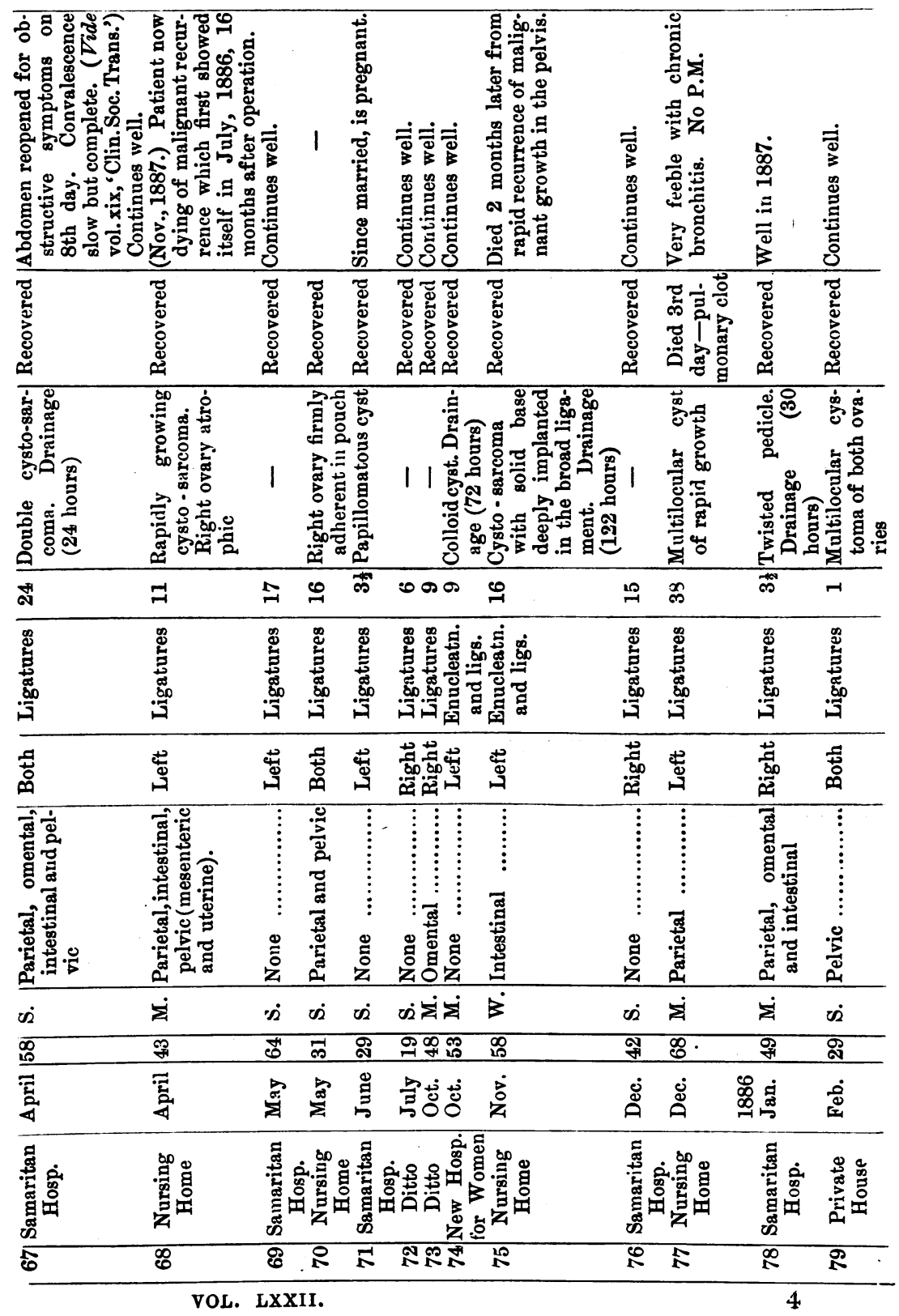




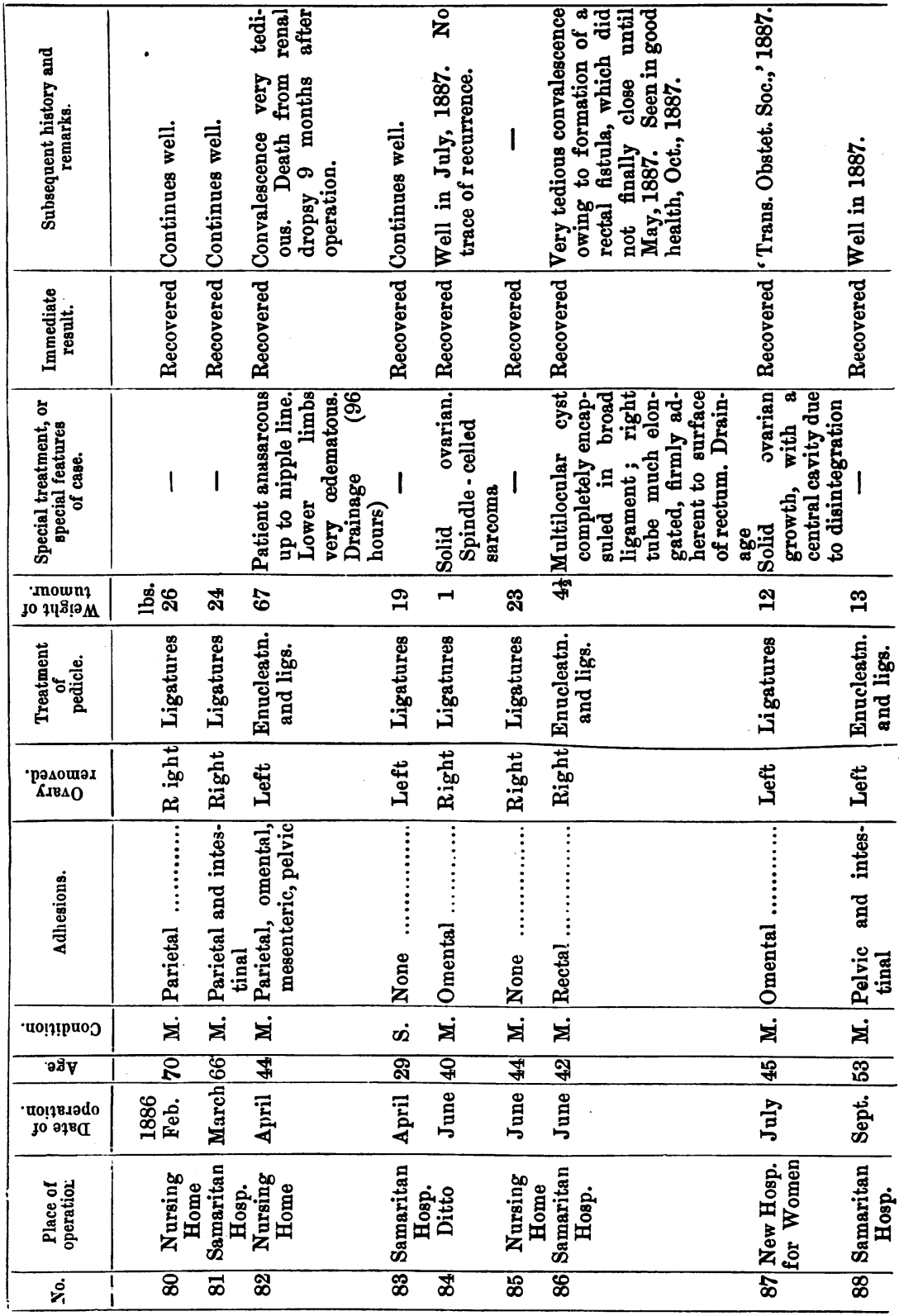




\begin{tabular}{|c|c|c|c|c|c|c|c|}
\hline 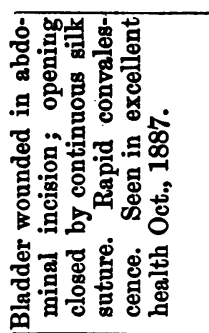 & 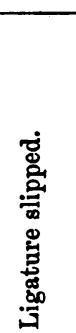 & 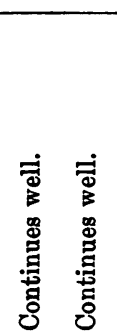 & 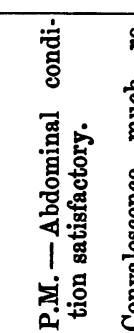 & 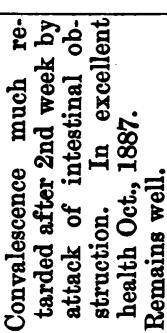 & 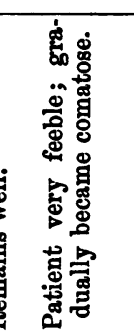 & 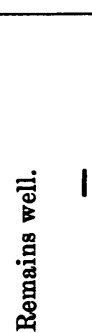 & 1 \\
\hline 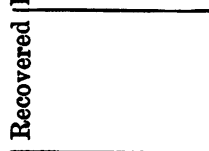 & 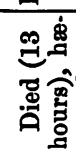 & 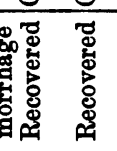 & 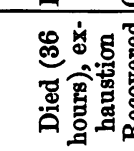 & & 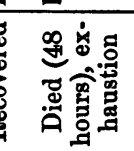 & & \\
\hline 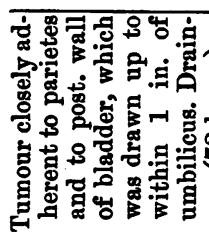 & & 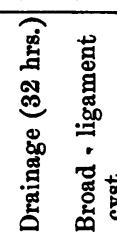 & 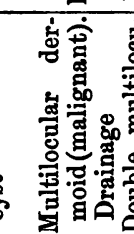 & 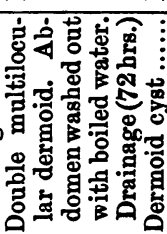 & 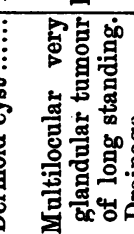 & & 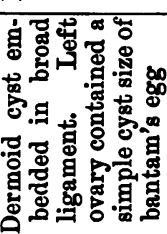 \\
\hline ๓ & $\Rightarrow$ & $\vec{a}$ & ה & I & 19 & $\infty \quad \infty$ & $\infty$ \\
\hline 悹 & 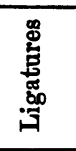 & 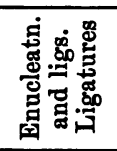 & 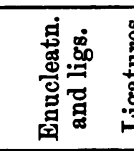 & 墨 & 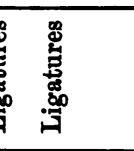 & 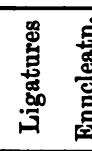 & 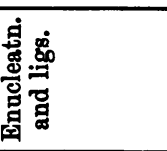 \\
\hline ક્ّ & 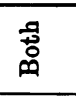 & 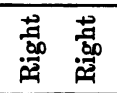 & 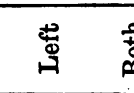 & 表 & 惫 & 蔒 & \\
\hline 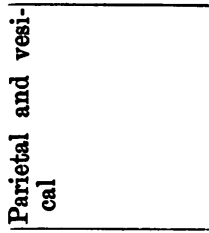 & 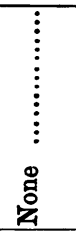 & 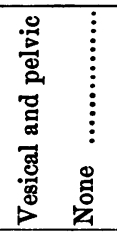 & 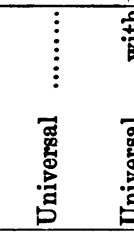 & 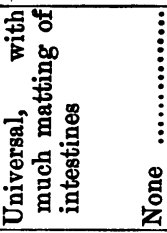 & 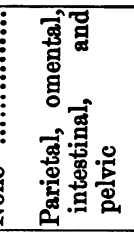 & 总 & \\
\hline$\dot{x}$ & $\dot{x}$ & $\dot{\dot{x}} \quad \dot{2}$ & $\dot{z}$ & $\dot{2}$ & $\dot{y}$ & $\dot{x}=$ & \\
\hline 表 & $\mathscr{C}_{0}$ & 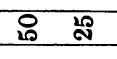 & 平 & 令 & 8 & $\mathscr{\mathscr { N }}$ & \\
\hline : & $\stackrel{8}{\circ}$ & 容容 & 商宫 & 递 & $\overline{\mathrm{E}}$ & $\stackrel{\Xi}{\sharp}$ & \\
\hline & 总 & 羙量 & 䙵 & 曾 & 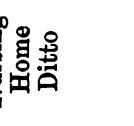 & & \\
\hline & 8 & $\vec{\sigma} \delta$ & 8 & F্ & 8 & $\delta \quad \alpha$ & \\
\hline
\end{tabular}




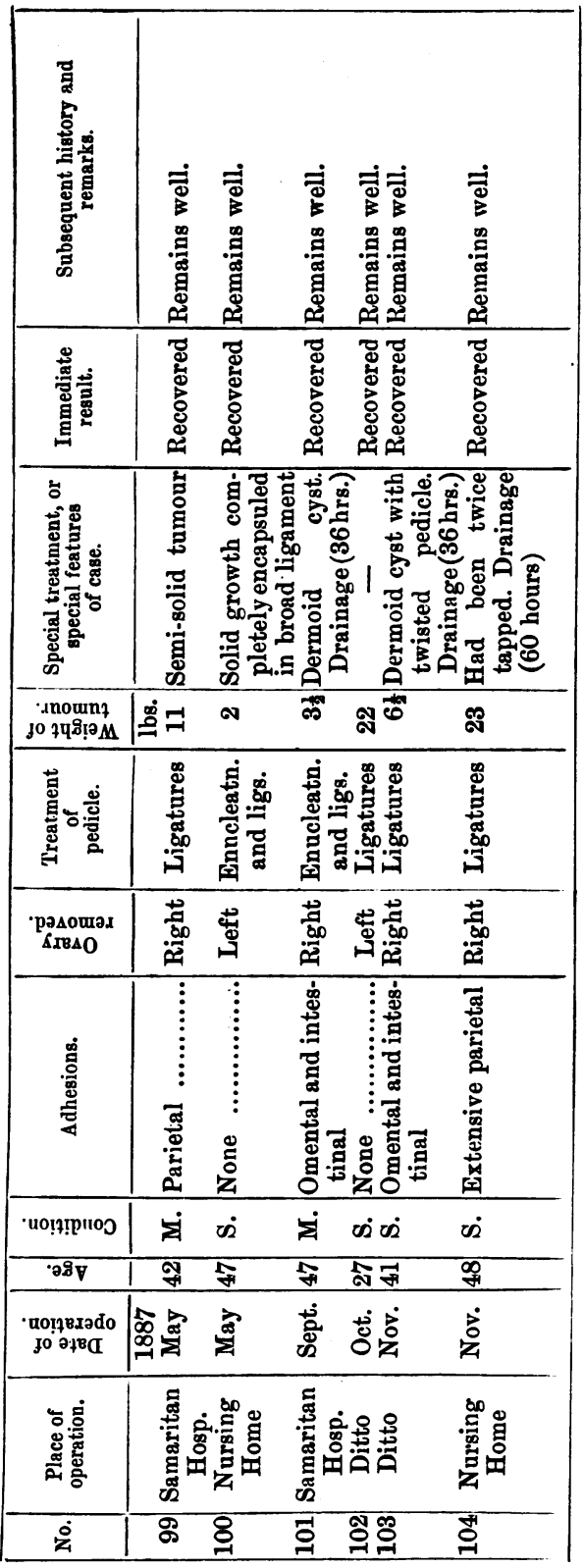

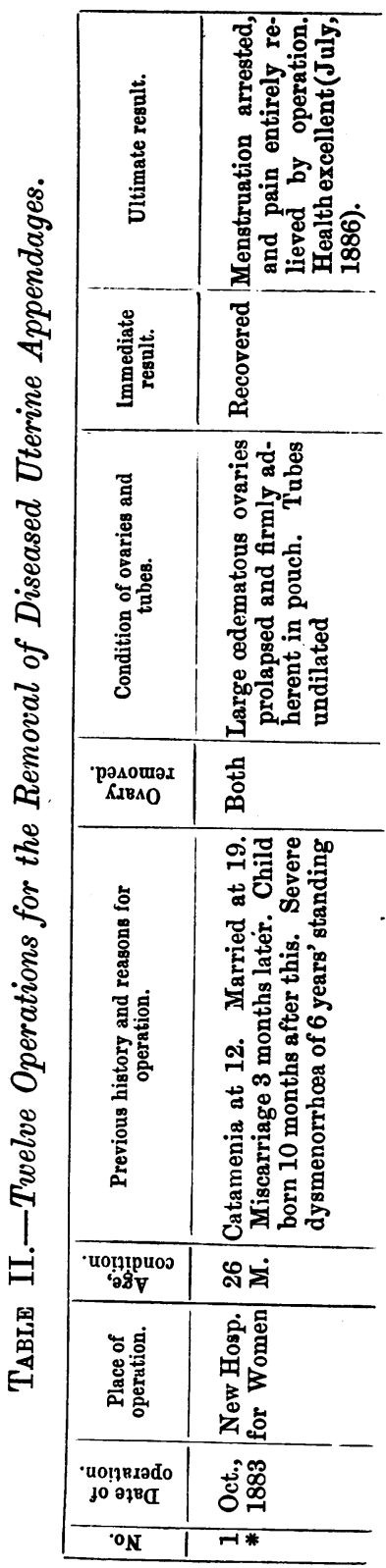




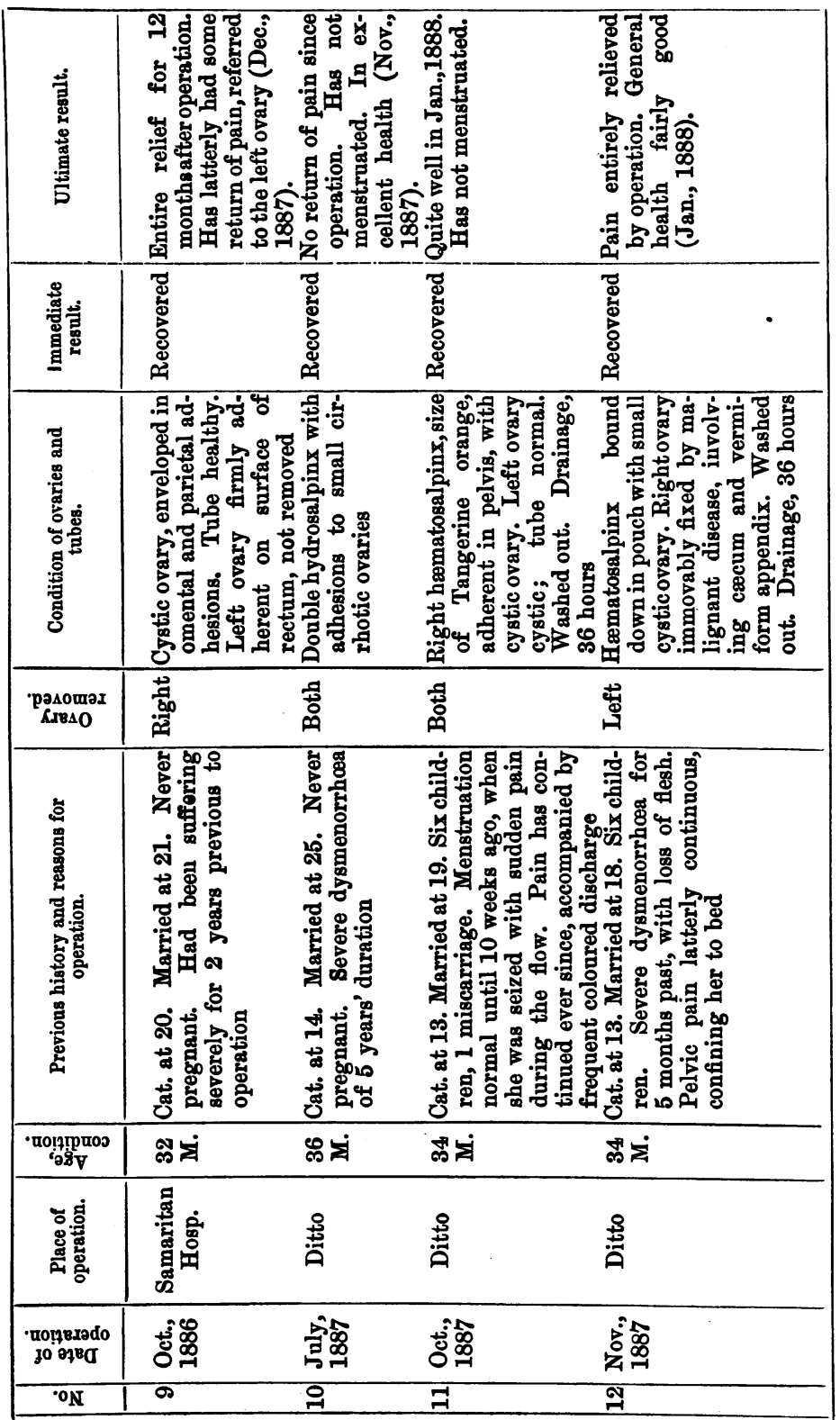


MORTALITY OF ABDOMINAL BECTION.
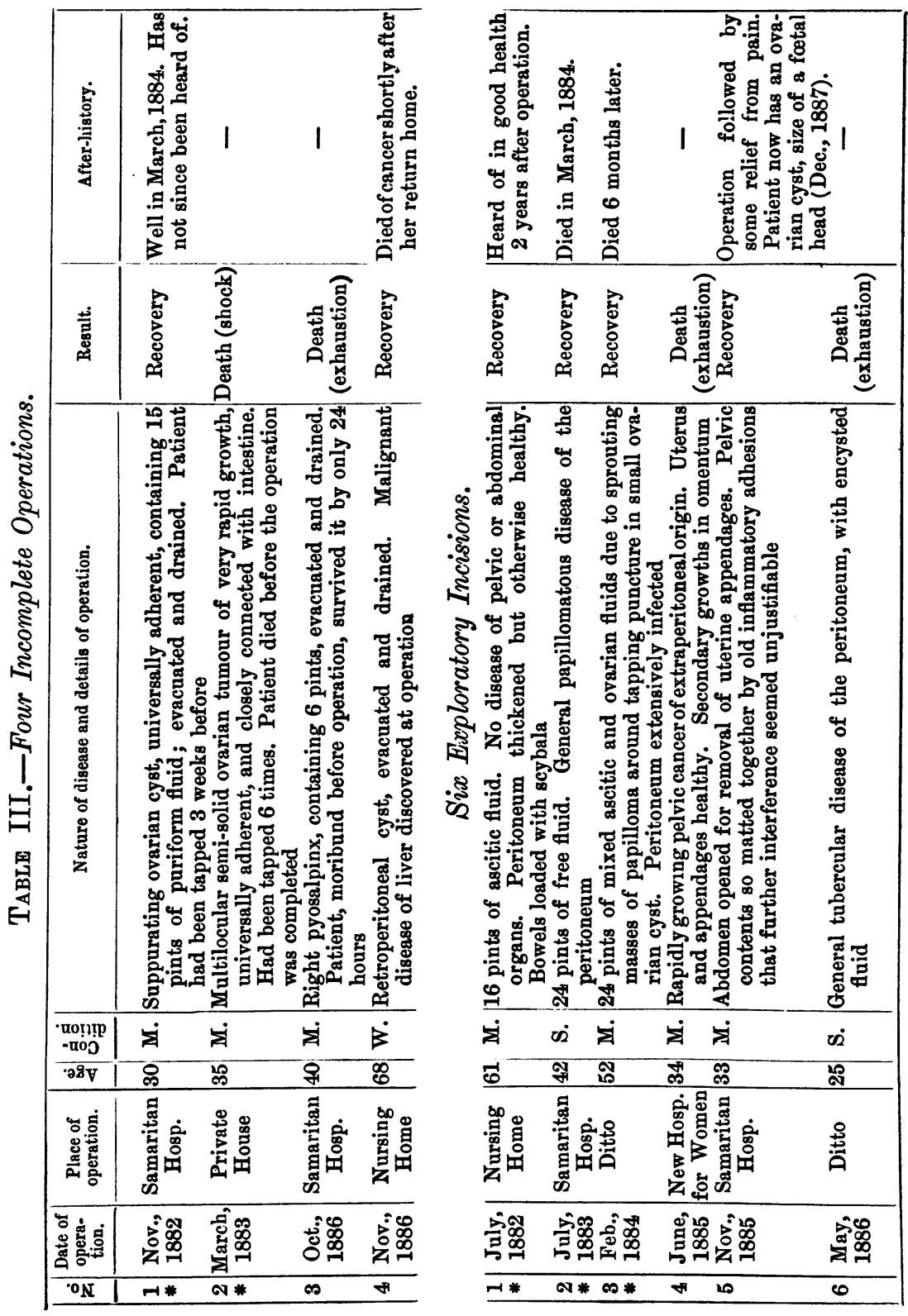

今े

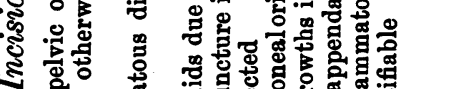

约

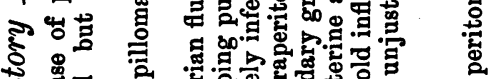

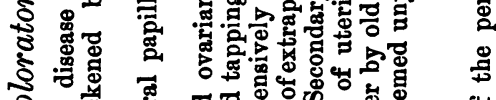

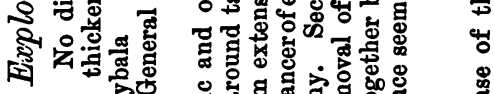

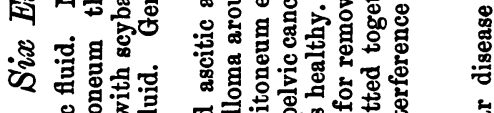

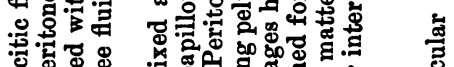

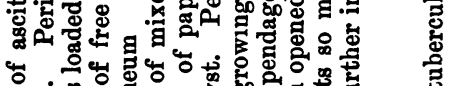

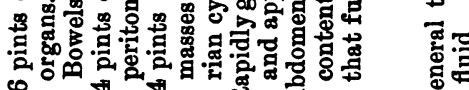

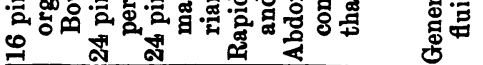

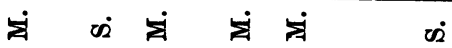

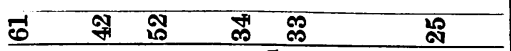

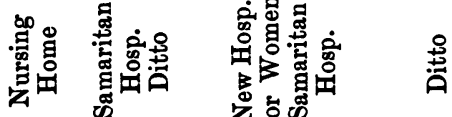

\begin{tabular}{|c|c|c|c|}
\hline 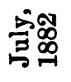 & 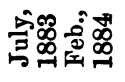 & 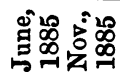 & 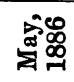 \\
\hline
\end{tabular}


(For report of the discussion on this paper, see 'Proceedings of the Royal Medical and Chirurgical Society,' Third Series, vol. i, p. 1.) 